\title{
A FLÓRULA DA RESERVA DUCKE, I: PALMAE (ARECACEAE).
}

\section{Andrew HENDERSON", Aldicir SCARIOT ${ }^{2}$}

RESUMO - Este é o primeiro tratamento taxonômico de uma família de angiospermas para a flórula da Reserva Ducke. A família está representada na Reserva por 35 espécies, distribuidas em 14 gêneros. Os gêneros com seus respectivos números de espécies são: Bactris (8), Geonoma (6), Astrocaryum (5), Attalea (3), Oenocarpus (3), Euterpe (2), Desmoncus (1), Hyospathe (1), Iriartella (1), Manicaria (1), Mauritia (1), Mauritiella (1), Socratea (1) e Syagrus (1). O tratamento inclui chaves para identificacão dos gêneros e das espécies encontrados na Reserva, além de descrições sucintas das espécies. As chaves utilizam, principalmente caracteres encontrados em material herborizado, em estado fértil.

Palavras-chave: Levantamento florístico, Amazônia Central, Palmae.

Florula of the Ducke Forest Reserve, I: PALMAE (ARECACEAE).

ABSTRACT - This is the first taxomomic treatment of a family for the Florula of the Ducke Reserve. Fourteen genera with 35 species are treated for the palm family, with keys to all genera and species and brief descriptions of all species. The keys are based on characters found on fertile herbarium specimens. Listed by decreasing diversity, the genera are: Bactris (8), Geonoma (6), Astrocaryum (5), Attalea (3), Oenocarpus (3), Euterpe (2), Desmoncus (1), Hyospathe (1), Iriartella (1), Manicaria (1), Mauritia (1), Mauritiella (1), Socratea (1) and Syagrus (1).

Key-words: Floristic Inventory, Central Amazonia, Palmae.

\section{INTRODUÇÃO}

O grande número de coletas herborizadas provenientes da região de Manaus (NELSON et al., 1990) torna este, o local mais indicado para a confecção deste primeiro manual de identificação. Entre vários locais e hábitats representativos próximos à Manaus, foi escolhida a Reserva Ducke ( 10.000 ha) para a elaboração deste guia, ou "flórula", pelas seguintes razões: 1) a área está bem documentada, com aproximadamente 6.000 exsicatas no herbário do INPA; 2) a cobertura vegetal predominante na Reserva é a floresta de terra firme, principal tipo de vegetação na Amazônia; 3) a Reserva está dotada de grande diversidade de árvores (ALENCAR, 1986); 4) a Reserva está situada no centro da Amazônia, portanto, inclui espécies representativas de outras regiões fitogeográficas da bacia (PRANCE, 1990); e, 5) a Reserva fica próxima ao INPA, facilitando a coleta de informações adicionais.

\section{MATERIAL E MÉTODOS}

Primeiramente foi examinado todo o material da família Palmae, herborizado no INPA. Entre 1987 e 1990 foram empreendidas três excur-

\footnotetext{
1 The New York Botanical Garden, Bronx, NY 10458 USA

2 CENARGEN/EMBRAPA, C.P. 102.372 - 70849 - Brasília, DF
} 
sões de campo, totalizando seis semanas de coletas e observações complementares, nos diferentes hábitats, dentro da Reserva. As coletas e observações foram feitas nos quadrantes noroeste e sudoeste da Reserva, sobre solos argilosos e arenosos, topografia de platô e de terreno dissecado, em ambientes de terra firme, baixio e margem de igarapé. Duplicatas de todas as espécies coletadas foram incorporadas nos herbários do INPA e do Jardim Botânico de Nova York, onde foram identificadas por comparação com material testemunho, revisado por especialistas. Coletas adicionais foram feitas $90 \mathrm{~km}$ ao norte de Manaus, na área do Projeto DBBF, o que permitiu melhor definição dos conceitos de classificação das palmeiras restritas à Reserva Ducke.

O tratamento está organizado em verbetes, ordenados hierarquicamente em três níveis: família, gênero e espécie, seguindo as normas padronizadas redigidas pelos coordenadores do projeto da flórula da Reserva, que tomaram como modelo o trabalho pioneiro de Lewis \& Owen (1989).

\section{RESULTADOS E DISCUSSÃO}

Foram coletadas e identificadas 35 espécies em 14 gêneros da família Palmae (Arecaceae). A análise das fotografias aéreas indica que os locais da Reserva não coletados, não acrescentam fisionomias florestais ou paisagens geomorfológicas diferentes daqueles visitados nas campanhas de coleta. E, embora este trabalho não venha a constituir um tratamento exaustivo do grupo, provavelmente inclui todas as espécies de palmeiras facilmente encontradas na Reserva.

\section{Tratamento Sistemático}

\section{PALMAE Jussieu}

Uhl, N. W. \& J. Dransfield. 1987. Genera Palmarum. The L. H. Bailey Hortorium \& The International Palm Society.

Estipes lenhosos, aéreos ou subterrâneos, solitários ou cespitosos, ocasionalmente trepadores, raramente ramificados. Folhas palmadas, costapalmadas, ou pinadas, induplicadas ou reduplicadas; bainhas abertas ou fechadas, quando fechadas formando uma coroa; pecíolos curtos ou longos; ráquis longos e contendo pinas em folhas pinadas, ou curtos ou ausentes em folhas palmadas e costapalmadas e, então, divididas em segmentos. Inflorescências inter ou infrafoliares na ântese; pedúnculos contendo um prófilo e uma a muitas brácteas pedunculares; ráquis contendo poucas a muitas ráquilas, ou ocasionalmente inflorescência espigada; flores geralmente trímeras, hermafroditas ou unissexuais e então plantas monóicas ou dióicas; frutos pequenos a muito grandes, geralmente com uma ou mais (2-10) sementes; sementes com endosperma homogêneo ou ruminado; eófilo inteiro, bífido, palmado, ou pinado.

Aproximadamente 200 gêneros e 2000 espécies no mundo; 71 gêneros e aproximadamente 800 espécies no Novo Mundo; 14 gêneros e 35 espécies na Reserva Florestal Ducke. Algumas palmeiras, tais como Bactris gasipaes 
e Leopoldinia piassava foram plantadas na Reserva Florestal Ducke, não fazendo parte, portanto, da flora nativa da Reserva. Certamente, outras espécies serão encontradas quando mais coletas forem realizadas.

1. Folhas palmadas; inflorescência com numerosas brácteas; plantas dióicas; frutos com escamas.

2. Estipes solitários, sem acúleos ou espinhos.

10. Mauritia

2. Estipes em touceiras, com acúleos no caule, os basais radiculares..... 11. Mauritiella

1. Folhas pinadas (ou com venação pinada se inteiras); inflorescência com 2 (raramente até 6) brácteas; plantas monóicas; frutos sem escamas.

3. Plantas sem espinhos no caule (ou espinhos presentes na raiz, ou pêlos híspidos no caule).

4. Estipes apoiados por raízes adventícias; inflorescência com 6 brácteas; margem foliar premorsa.

5. Estipes grandes e solitários, apoiados por um proeminente cone de raízes adventícias

13. Socratea

5. Estipes inclinados e em touceiras, apoiados por um cone inconspícuo de raízes adventícias

8. Iriartella

4. Estipes não apoiados por raízes adventícias; inflorescências com 2 brácteas; margem foliar lisa.

6. Palmeiras pequenas, do sub-bosque; flores em pequenas cavidades na ráquila 6. Geonoma

6. Palmeiras pequenas à grandes; flores encaixadas superficialmente na ráquila, nunca em cavidades.

7. Frutos sem endocarpo lenhoso com 3 poros.

8. Epicarpo com protuberâncias 9. Manicaria

8. Epicarpo liso, nunca com protuberâncias.

9. Inflorescências em forma de rabo-de-cavalo, as ráquilas pendentes 12. Oenocarpus

9. Inflorescências não em forma de um rabo-de- cavalo, ráquilas espalhadas.

10. Estipes altos, solitários ou cespitosos, com coroa foliar proeminente; pinas estreitas e regularmente dispostas; frutos globosos 5. Euterpe

10. Estipes pequenos, cespitosos, sem coroa foliar proeminente; pinas largas irregulares; frutos alongados 7. Hyospathe 
7. Frutos com endocarpo lenhoso, com poros.

11. Inflorescência sempre de um tipo, com flores estaminadas e pistiladas,estas basais

14. Syagrus

11.Inflorescências de dois tipos, ou predominantemente estaminada ou predominantemente pistilada 2. Attalea

3. Plantas com espinhos no caule; evidentes ou inconspícuos nas folhas. 12.Estipes inclinados e trepadores; pina distal modificada em gancho 4. Desmoncus

12.Estipes não trepadores; pina distal não modificada em gancho.

13.Flores pistiladas $1-5$, proximais na ráquila; flores estaminadas todas distais; superfície abaxial da folha glauca ...1. Astrocaryum

13.Flores pistiladas por toda a ráquila, não somente proximal; flores estaminadas não todas distais; superfície abaxial da folha esverdeada

3. Bactris

\section{ASTROCARYUM Meyer}

Kahn, F. \& B. Millán. 1992. Astrocaryum (Palmae) in Amazonia - a preliminary treatment. Bull. Inst. fr. études andines. 21: 459-531.

Gênero com cerca de 20 espécies nos trópicos da América Central e do Sul.

1. Estipes das plantas adultas curtos e subterrâneos.

2. Pinas regularmente dispostas todas em um plano 5. A. sciophilum

2. Pinas agrupadas e dispostas em vários planos 1. A, acaule

1. Estipes das plantas adultas longos e aéreos.

3. Estipes agrupados com brotações basais 4. A. gynacanthum

3. Estipes solitários sem brotaçães basais.

4. Pinas regularmente dispostas e em um plano 3. A. ferrugineum

4. Pinas agrupadas e dispostas em vários planos 2. A. aculeatum

1. Astrocaryum acaule Mart., Hist. Nat. Palm. 2: 78. (1824).

Estipe solitário, subterrâneo. Folhas 5-10; bainha aberta, até $1 \mathrm{~m}$ de comprimento; pecíolo $2-3 \mathrm{~m}$ de comprimento; ráquis $2,5-4 \mathrm{~m}$ de comprimento; pinas 55-180 por lado, agrupadas e espalhadas em diferentes planos. Inflorescência interfoliar, ereta; pedúnculo $80-130 \mathrm{~cm}$ de comprimento; prófilo $25-50 \mathrm{~cm}$ de comprimento, bráctea peduncular $45-50 \mathrm{~cm}$ de comprimento, persistente, curvada, com listras marrons e espinhos na superfície externa; flores estaminadas com 3 sépalas, 3 pétalas, e 6 estames; flores pistiladas 2-3 na base de cada ráquila, com um cálice cupular e corola; frutos 
ovóides a subglobosos, $2-2,5 \mathrm{~cm}$ de diâmetro, sem espinhos, marromlaranja na maturidade.

Comum em áreas perturbadas, margens de riachos e outras áreas abertas da floresta tropical úmida, através do Norte da América do Sul. Na Reserva Ducke somente ocorre em áreas perturbadas.

2. Astrocaryum aculeatum G. F. W. Meyer, Prim. Fl. Essequib. 266. (1818).

Astrocaryum tucuma Mart., Hist. Nat. Palm. 2: 77. (1824).

\section{"Tucumã"}

Estipe solitário, até $20 \mathrm{~m}$ de altura, até $30 \mathrm{~cm}$ de diâmetro, com internós densamente espinhosos. Folhas 6-15, muito espinhosas; bainha e pecíolo 2-5 m de comprimento; ráquis 3,5 $5,5 \mathrm{~m}$ de comprimento; pinas 100-175 por lado, agrupadas e dispostas em diferentes ângulos, prateadas na face abaxial. Inflorescências eretas, interfoliares; pedúnculo ca. $2,5 \mathrm{~m}$ de comprimento; prófilo ca. de $85 \mathrm{~cm}$ de comprimento; bráctea peduncular ca. de 1,6 $\mathrm{m}$ de comprimento; ráquis até $1,5 \mathrm{~m}$ de comprimento; ráquilas 150 250; flores estaminadas ca. $5 \mathrm{~mm}$ de comprimento, com 3 sépalas, 3 pétalas e 6 estames; flores pistiladas 2-4 na base de cada ráquila; sépalas e pétalas subiguais, urceoladas; anel estaminodal ca. de $2 \mathrm{~mm}$ de altura; fruto subgloboso a ovóide, $4-5 \times 6-7 \mathrm{~cm}$.

Comum, especialmente em áreas perturbadas próximo a ocupação humana, através do norte da América do Sul. Os exemplares na Reserva Ducke podem ter sido plantados.
Os frutos são vendidos em mercados, e as fibras das folhas são usadas para trançar redes e outros artigos.

Henderson \& Scariot 1175 (est.).

3. Astrocaryum ferrugineum Kahn \& Millán, Bull. Inst. fr. études andines 21: 497. (1992).

\section{"Murumuru",}

Estipe solitário, 5-9 $\mathrm{m}$ de altura, $18-35 \mathrm{~cm}$ de diâmetro, coberto com longos espinhos negros, caducos nos indivíduos maiores que $5 \mathrm{~m}$ de altura. Folhas espalhando-se; bainha e pecíolo ca. de $2 \mathrm{~m}$ de comprimento, muito espinhosos; ráquis até $6 \mathrm{~m}$ de comprimento; pinas 100-128 por lado, lineares, regularmente espaçadas e todas em um plano, prateadas na face abaxial. Inflorescências interfoliares; pedúnculo ca. de $1,3 \mathrm{~m}$ de comprimento; prófilo ca. de $1 \mathrm{~m}$ de comprimento; bráctea peduncular até $1,2 \mathrm{~m}$ de comprimento; ráquis ca. de $50 \mathrm{~cm}$ de comprimento; ráquilas até 250 , com uma flor pistilada na base de cada uma; flores estaminadas com 3 sépalas, 3 pétalas, e 6 estames; flores pistiladas com cálice cupular e corola; frutos obovóides ou malformados, $3 \times 5 \mathrm{~cm}$, densamente a moderadamente coberto com espínulos.

Espécie conhecida somente das proximidades de Manaus.

Henderson 674 (fr).

4. Astrocaryum gynacanthum Mart., Hist. Nat. Palm. 2:71. (1824).

Astrocaryum munbaca Mart., Hist. Nat. Palm. 2:74. (1824).

"Mumbaca". 
Estipes cespitosos, 6-10 m de altura, ca. de $5 \mathrm{~cm}$ de diâmetro, com longos espinhos negros nos internós. Folhas 6-13; bainhas abertas, espinhosas, $40-80 \mathrm{~cm}$ de comprimento; pecíolo espinhoso, $60-75 \mathrm{~cm}$ de comprimento; ráquis $2,3-2,5 \mathrm{~m}$ de comprimento; pinas $21-40$ por lado, regularmente espaçadas e em um plano, lineares, prateadas na face abaxial. Inflorescência interfoliar, espinhosa em todas as partes; pedúnculo arqueado, $70-80 \mathrm{~cm}$ de comprimento; prófilo $40-50 \mathrm{~cm}$ de comprimento; bráctea peduncular 70$80 \mathrm{~cm}$ de comprimento, persistente; ráquis $20-24 \mathrm{~cm}$ de comprimento; ráquilas até $100 \mathrm{com} 1$ flor pistilada na base e flores estaminadas acima; flores estaminadas com 3 sépalas, 3 pétalas, e 6 estames; flores pistiladas com cálice cupular e corola; fruto ovóide, $1,2 \times 2 \mathrm{~cm}$; epicarpo avermelhado, com fendas quando maduro.

Muito comum no sub-bosque de terra firme da floresta tropical úmida na Amazônia.

Henderson 675 (est.)

5. Astrocaryum sciophilum (Miq.) Pulle, Enum. Vasc. Pl. Surinam 73. (1906).

Bactris sciophila Miq., Natuurk. Verh. Kon. Maatsch. Wetensh. Haarlem 7: 208. (1851).
Astrocaryum sociale Barb. Rodr., Vellosia 1: 48. (1888).

Estipe solitário, subterrâneo. Folhas 7-12, eretas; pecíolo e bainha até $1,5 \mathrm{~m}$ de comprimento, com anéis de espinhos; ráquis 4-4,7 $\mathrm{m}$ de comprimento; pinas 58-100, regularmente dispostas e em um plano, lineares, cinza na face abaxial. Inflorescência interfoliar; pedúnculo ca. de $90 \mathrm{~cm}$ de comprimento; bráctea peduncular ca. de $75 \mathrm{~cm}$ de comprimento, densamente espinhosa na superfície abaxial; ráquis ca. $15 \mathrm{~cm}$ de comprimento; ráquilas numerosas, cada com uma flor pistilada na base; flores estaminadas com 3 sépalas, 3 pétalas, e 6 estames; flores pistiladas com cálice cupular e corola; frutos obovóides, $3-4 \times 6 \mathrm{~cm}$, cobertos com espinhos negros, curtos.

Comum na terra firme na floresta tropical úmida, na Amazônia.

Henderson 680 (fr.); Henderson \& Scariot 1158 (fr.).

\section{ATTALEA Kunth.}

Os gêneros Maximiliana, Scheelea, Orbignya e Attalea têm sido artificialmente mantidos, com base na morfologia da flor estaminada. Entretanto, existem agora intermediários conhecidos entre todos eles, não sendo possível mantê-los separados (Henderson \& Balick, 1991).

1. Estipes bem desenvolvidos, estames exsertos 2. A. maripa

1. Estipes subterrâneos; estames inclusos.

2. Pétalas das flores estaminadas lineares, arredondadas ou angulares em seção transversal; anteras retas. 1. A. attaleoides

2. Pétalas das flores estaminadas espatuladas, côncavas, lineares em seção transversal; anteras irregularmente espiraladas ou torcidas. 3. A. spectabilis 
1. Attalea attaleoides (Barb. Rodr.) W. Boer, Flora of Suriname 5(1): 157. (1965).

Maximiliana attaleoides Barb. Rodr., Enum. Palm. Nov. 41. (1875).

"Palha branca".

Estipe solitário, subterrâneo. Folhas 8-14; bainha aberta, ca. de 50 $\mathrm{cm}$ de comprimento; pecíolo 80-100 $\mathrm{cm}$ de comprimento; ráquis $5-9 \mathrm{~m}$ de comprimento, castanho-clara na face abaxial; pinas $75-136$ por lado, igualmente espaçadas e todas no mesmo plano, lineares. Inflorescência interfoliar, predominantemente estaminada ou predominantemente pistilada, raramente hermafrodita, e ambos os tipos ocorrendo na mesma planta; pedúnculo ca. de $50 \mathrm{~cm}$ de comprimento; prófilo ca. de $50 \mathrm{~cm}$ de comprimento; bráctea peduncular 70-120 cm de comprimento, lenhosa, fendas longas e finas na superfície externa; ráquis $30-50 \mathrm{~cm}$ de comprimento; ráquilas das inflorescências masculinas ca. de 100; flores estaminadas com sépalas até 1 $\mathrm{mm}$ de comprimento e pétalas achatadas de até $10 \mathrm{~mm}$ de comprimento; estames 6, 3-4 $\mathrm{mm}$ de comprimento; flores pistiladas com anel estaminodal; fruto oblongo, 2-2,5 $\times 4-5 \mathrm{~cm}$, marrom.

Geralmente restrita à terra firme de floresta tropical úmida, na Amazônia.

Henderson 656 (fl.); Henderson \& Scariot 1170 (fl.).

2. Attalea maripa (Aublet) Mart. in Orbigny, Voy. Amérique Mér. 7(3). Palmiers 123. (1844).

Palma maripa Aublet, Hist. pl. Guiane 2: 974. (1775).
Maximiliana maripa (Aublet) Drude in Mart., Fl. Bras.: Palmae II 3(2): 452. (1881).

\section{"Inajá".}

Estipe solitário, até $20 \mathrm{~m}$ de altura, até $35 \mathrm{~cm}$ de diâmetro. Folhas 13-22, inseridas em 5-7 espirais; bainha e pecíolo até $4 \mathrm{~m}$ de comprimento; ráquis 6-10 $\mathrm{m}$ de comprimento; pinas 220-260 por lado, agrupadas e dispostas em diferentes ângulos. Inflorescência interfoliar, ou predominantemente estaminada ou predominantemente pistilada, e ambos os tipos ocorrendo na mesma planta; pedúnculo até $1 \mathrm{~m}$ de comprimento; prófilo ca. de $60 \mathrm{~cm}$ de comprimento; bráctea peduncular de até $2 \mathrm{~m}$ de comprimento, espessa e lenhosa; flores estaminadas com 6 estames, estes excedendo em muito as pétalas e sépalas; flores pistiladas com anel estaminodal; fruto oblongo, 1-3 sementes, $2,5 \times 5 \mathrm{~cm}$.

Distribuída na floresta tropical úmida em áreas abertas no Norte da América do Sul. Muito comum em áreas perturbadas.

Henderson \& Scariot 1174 (est.).

3. Attalea spectabilis Mart., Hist. Nat. Palm. 2: 136. (1826).

Orbignya spectabilis (Mart.) Burret, Notizbl. Bot. Gart. BerlinDahlem 10: 508. (1929).

"Palha vermelha".

Estipe solitário, subterrâneo. Folhas 7-9; bainha aberta, ca. $50 \mathrm{~cm}$ de comprimento; pecíolo ca. de $2 \mathrm{~m}$ de comprimento; ráquis 4-5 $\mathrm{m}$ de comprimento, ferrugíneo na face abaxial; pinas 75-115 por lado, regularmente 
espaçadas e em um plano. Inflorescência interfoliar, predominantemente estaminada ou predominantemente pistilada, ambos os tipos ocorrendo na mesma planta; pedúnculo ca. de $70 \mathrm{~cm}$ de comprimento; prófilo ca. de $1 \mathrm{~m}$ de comprimento; bráctea peduncular ca. de $1 \mathrm{~m}$ de comprimento; ráquis 45-50 $\mathrm{cm}$ de comprimento; ráquilas 14-75; flores estaminadas densamente agrupadas na ráquila; sépalas muito curtas; pétalas espatuladas, incurvadas; estames torcidos, 11-15; flores pistiladas com mais ou menos o mesmo número de sépalas e pétalas; anel estaminodal presente; fruto ovóide ou sub-globoso, $3 \times 3,5-4 \mathrm{~cm}$.

Geralmente confinada à áreas inundadas ou áreas arenosas abertas, próximas a riachos, através do vale amazônico.

Henderson 668 (fl.); Henderson \& Scariot 1165 (f1.).

\section{BACTRIS Jacq. ex Scop.}

Burret, M, 1934. Bactris und verwandte Palmengattungen. Repert. Spec. Nov. Regni Veg. 34: 167-184, 186-253.

Gênero com menos de 100 espécies (embora mais de 250 nomes), distribuídos pelos Neotrópicos, desde o Sul do México até Paraguai e Sul do Brasil, e também no Caribe.

Bactris gasipaes é cultivada na R.F. Ducke. Provavelmente, mais de oito espécies nativas serão encontradas na Reserva, após coletas mais intensivas.

1. Inflorescência com poucas ráquilas, geralmente 1-3.

2. Frutos negro-purpúreos.

3. Flores femininas e frutos com um anel estaminodal; caules curtos, até $50 \mathrm{~cm}$ altura 3. B. gastoniana

3. Flores femininas e frutos sem um anel estaminodal; caules de 1,2-3,5 $m$ altura.

4. Pinas numerosas, regularmente dispostas (mas com algumas falhas), bífidas no ápice

2. B. elegans

4. Pinas poucas, irregularmente dispostas, longo-acuminadas no ápice 8. B. sphaerocarpa

2. Frutos vermelhos.

5. Frutos espinhosos; pinas tomentosas; inflorescência ereta na ântese e na frutificação 4. B. hirta

5. Frutos não espinhosos; pinas não tomentosas; inflorescência pendente na ântese e na frutificação 7. B. simplicifrons

1. Inflorescência com numerosas ráquilas.

6. Frutos glabros, negro-purpúreos 6. B. monticola

6. Frutos espinhosos, avermelhados.

7. Estipes bem desenvolvidos 1. B. acanthocarpoides

7. Estipes curto se subterrâneos 5. B. humilis 
1. Bactris acanthocarpoides Barb. Rodr., Enum. Palm. Nov. 33. (1875).

\section{"Marajá".}

Estipe cespitoso, até $6 \mathrm{~m}$ de altura, $3-5 \mathrm{~cm}$ de diâmetro, espinhoso. Folhas 7-12; bainha $40-60 \mathrm{~cm}$ de comprimento; pecíolo $40-90 \mathrm{~cm}$ de comprimento; ráquis $110-200 \mathrm{~cm}$ de comprimento; pinas $30-40$ por lado, mais ou menos no mesmo plano, um pouco agrupadas, lineares a sigmóides. Inflorescências interfoliares; pedúnculo 20-25 cm de comprimento; prófilo 10$20 \mathrm{~cm}$ de comprimento; bráctea peduncular $20-30 \mathrm{~cm}$ de comprimento, densamente espinhosa na superfície abaxial; ráquis $5-10 \mathrm{~cm}$ de comprimento; ráquilas numerosas; flores estaminadas com 3 sépalas, 3 pétalas e 6 estames; flores pistiladas com cálice cupular e corola; frutos globosocomprimidos, 1,2-1,6 cm de diâmetro, com espínulos, vermelho-laranja na maturidade.

Distribuída no vale amazônico, geralmente em locais úmidos próximo a riachos.

Henderson \& Scariot 1160 (fr.); Moore et al. 9529 (fr.).

2. Bactris elegans Barb. Rodr. \& Trail ex Barb. Rodr., Enum. Palm. Nov. 35. (1875).

\section{"Marajá".}

Estipes solitários ou cespitosos, 3$3,5 \mathrm{~m}$ de altura, $1-1,5 \mathrm{~cm}$ de diâmetro. Folhas 7-13; bainhas abertas, $20-30 \mathrm{~cm}$ de comprimento; pecíolo $30-40 \mathrm{~cm}$ de comprimento; ráquis $70-75 \mathrm{~cm}$ de comprimento; pinas 23-32 por lado, lanceoladas, bífidas no ápice, regular- mente espaçadas mas falhas, todas no mesmo plano. Inflorescências interfoliares; pedúnculo até $25 \mathrm{~cm}$ de comprimento; prófilo $14-20 \mathrm{~cm}$ de comprimento; bráctea peduncular $35-40 \mathrm{~cm}$ de comprimento, densamente coberta com espinhos marrons; ráquis muito curto; ráquilas 2; flores estaminadas com cálice anelado e 3 pétalas unidas na base; estames 6 ; flores pistiladas espalhadas entre estaminadas, pareadas ou solitárias; cálice e corola urceolada, mais ou menos igual em comprimento; anel estaminodal ausente; fruto globoso, negro-purpúreo, $1,5 \mathrm{~cm}$ de diâmetro.

Norte do Brasil e Guianas, em terra firme na floresta tropical úmida.

Balick et al. 967 (fr.); Henderson 654 (fr.); Henderson \& Scariot 1155 (fl.).

3. Bactris gastoniana Barb. Rodr., . Vellosia 1: 40. (1880).

\section{"Marajá".}

Estipe solitário ou cespitoso, subterrâneo ou até $50 \mathrm{~cm}$ de comprimento, até $1 \mathrm{~cm}$ de diâmetro. Folhas até 9 ; bainhas abertas, até $25 \mathrm{~cm}$ de comprimento; pecíolos até $70 \mathrm{~cm}$ de comprimento; ráquis até $60 \mathrm{~cm}$ de comprimento; pinas até 11 por lado, agrupadas em grupos de 2. Inflorescência interfoliar; pedúnculo até $20 \mathrm{~cm}$ de.comprimento; prófilo até $10 \mathrm{~cm}$ de comprimento; bráctea peduncular até $25 \mathrm{~cm}$ de comprimento, a parte externa densamente coberta com espinhos negros ou marrons; ráquis não ramificado; flores estaminadas com cálice anelar; pétalas muito mais longas que o cálice e conatas somente na base; esta-mes 6; flores pistiladas distribuídas entre as estaminadas; cálice e corola iguais em 
comprimento; anel estaminodal ca. de 0,5 mm de altura; fruto elipsóide, negro, 0,8 $\times 2,5 \mathrm{~cm}$, endosperma homogêneo.

Bacia amazônica e Guianas, na terra firme em floresta tropical úmida.

Henderson 658 (fr.); Henderson \& Scariot 1162 (fr.).

4. Bactris hirta Mart., Hist, Nat. Palm. 2: 104. (1823).

\section{"Marajá".}

Estipe solitário ou cespitoso, até 2 $m$ de altura, até $1 \mathrm{~cm}$ de diâmetro. Folhas até 7; bainha aberta, até $20 \mathrm{~cm}$ de comprimento; pecíolo até $25 \mathrm{~cm}$ de comprimento; ráquis até $50 \mathrm{~cm}$ de comprimento; pinas de diferentes larguras e irregularmente dispostas, ou todas unidas em uma folha inteira bífida no ápice, folha hirta na face abaxial. Inflorescência infrafoliar, ereta na ântese e frutificação; bráctea peduncular até 8 $\mathrm{cm}$ de comprimento, densamente coberta externamente com espinhos negros; ráquilas 2-3; flores estaminadas com cálice trilobado; pétalas unidas na base; estames 6; flores pistiladas regularmente dispostas na base das ráquilas; cálice pequeno, anelar; corola mais comprida, urceolada; fruto globoso, vermelho a quase negro quando maduro, $6-7 \mathrm{~mm}$ de diâmetro.

Distribuída no norte da América do Sul, em terra firme na floresta tropical úmida.

Henderson 666 (fl.); Henderson 667 (fl.); Henderson \& Scariot 1151 (fl.).

5. Bactris humilis (Wallace) Burret, Feddes Rep. 34: 182. (1933).

Astrocaryum humile Wallace, Palm Trees of the Amazon 15. (1953).
"Marajá".

Estipe solitário ou cespitoso, subterrâneo ou ocasionalmente até 50 $\mathrm{cm}$ de altura, até $4 \mathrm{~cm}$ de diâmetro. Folhas até 12 ; bainhas abertas, até 30 cm de comprimento; pecíolo até $1,4 \mathrm{~m}$ de comprimento; ráquis até $1,7 \mathrm{~m}$ de comprimento; pinas até 20 por lado, agrupadas, mas mais ou menos no mesmo plano, sigmóides. Inflorescências interfoliares; pedúnculo até 17 $\mathrm{cm}$ de comprimento; prófilo até $10 \mathrm{~cm}$ de comprimento; bráctea peduncular até $20 \mathrm{~cm}$ de comprimento, densamente espinhosa na superfície externa; ráquis até $5 \mathrm{~cm}$ de comprimento; ráquilas até 40 , inclinada; flores estaminadas com 6 estames; flores pistiladas regularmente dispostas na base das ráquilas; sépalas e pétalas urceoladas, corola muito mais longa que o cálice; anel estaminodal ausente; fruto globoso, 1 $\mathrm{cm}$ de diâmetro, vermelho-laranja quando maduro, coberto com espinhos curtos; endosperma homogêneo.

Distribuída no Norte da América do Sul, ocorrendo em terra firme na floresta tropical úmida.

Henderson 657 (fr.); Henderson 671 (fr.); Henderson \& Scariot 1159 (fr.).

6. Bactris monticola Barb. Rodr. Enum. Palm. Nov, 34. (1875).

"Marajá".

Estipes cespitosos, 6-7 $\mathrm{m}$ de altura, 3-5 cm de diâmetro. Folhas 5-9; bainhas abertas, com espinhos amarelados fortemente achatados; pecíolo 50$60 \mathrm{~cm}$ de comprimento, com espinhos similares aos da bainha; ráquis 130- 
1. Bactris acanthocarpoides Barb. Rodr., Enum. Palm. Nov. 33. (1875).

\section{"Marajá".}

Estipe cespitoso, até $6 \mathrm{~m}$ de altura, $3-5 \mathrm{~cm}$ de diâmetro, espinhoso. Folhas 7-12; bainha $40-60 \mathrm{~cm}$ de comprimento; pecíolo $40-90 \mathrm{~cm}$ de comprimento; ráquis $110-200 \mathrm{~cm}$ de comprimento; pinas $30-40$ por lado, mais ou menos no mesmo plano, um pouco agrupadas, lineares a sigmóides. Inflorescências interfoliares; pedúnculo 20-25 cm de comprimento; prófilo 10$20 \mathrm{~cm}$ de comprimento; bráctea peduncular $20-30 \mathrm{~cm}$ de comprimento, densamente espinhosa na superfície abaxial; ráquis $5-10 \mathrm{~cm}$ de comprimento; ráquilas numerosas; flores estaminadas com 3 sépalas, 3 pétalas e 6 estames; flores pistiladas com cálice cupular e corola; frutos globosocomprimidos, 1,2-1,6 cm de diâmetro, com espínulos, vermelho-laranja na maturidade.

Distribuída no vale amazônico, geralmente em locais úmidos próximo a riachos.

Henderson \& Scariot 1160 (fr.); Moore et al. 9529 (fr.).

2. Bactris elegans Barb. Rodr. \& Trail ex Barb. Rodr., Enum. Palm. Nov, 35 . (1875).

\section{"Marajá".}

Estipes solitários ou cespitosos, 33,5 $\mathrm{m}$ de altura, $1-1,5 \mathrm{~cm}$ de diâmetro. Folhas 7-13; bainhas abertas, $20-30 \mathrm{~cm}$ de comprimento; pecíolo $30-40 \mathrm{~cm}$ de comprimento; ráquis $70-75 \mathrm{~cm}$ de comprimento; pinas 23-32 por lado, lanceoladas, bífidas no ápice, regular- mente espaçadas mas falhas, todas no mesmo plano. Inflorescências interfoliares; pedúnculo até $25 \mathrm{~cm}$ de comprimento; prófilo $14-20 \mathrm{~cm}$ de comprimento; bráctea peduncular $35-40 \mathrm{~cm}$ de.comprimento, densamente coberta com espinhos marrons; ráquis muito curto; ráquilas 2; flores estaminadas com cálice anelado e 3 pétalas unidas na base; estames 6 ; flores pistiladas espalhadas entre estaminadas, pareadas ou solitárias; cálice e corola urceolada, mais ou menos igual em comprimento; anel estaminodal ausente; fruto globoso, negro-purpúreo, $1,5 \mathrm{~cm}$ de diâmetro.

Norte do Brasil e Guianas, em terra firme na floresta tropical úmida.

Balick et al, 967 (fr.); Henderson 654 (fr.); Henderson \& Scariot 1155 (fl.).

3. Bactris gastoniana Barb. Rodr., . Vellosia 1: 40. (1880).

\section{"Marajá".}

Estipe solitário ou cespitoso, subterrâneo ou até $50 \mathrm{~cm}$ de comprimento, até $1 \mathrm{~cm}$ de diâmetro. Folhas até 9 ; bainhas abertas, até $25 \mathrm{~cm}$ de comprimento; pecíolos até $70 \mathrm{~cm}$ de comprimento; ráquis até $60 \mathrm{~cm}$ de comprimento; pinas até 11 por lado, agrupadas em grupos de 2. Inflorescência interfoliar; pedúnculo até $20 \mathrm{~cm}$ de.comprimento; prófilo até $10 \mathrm{~cm}$ de comprimento; bráctea peduncular até $25 \mathrm{~cm}$ de comprimento, a parte externa densamente coberta com espinhos negros ou marrons; ráquis não ramificado; flores estaminadas com cálice anelar; pétalas muito mais longas que o cálice e conatas somente na base; esta-mes 6; flores pistiladas distribuídas entre as estaminadas; cálice e corola iguais em 
comprimento; anel estaminodal ca. de 0,5 mm de altura; fruto elipsóide, negro, 0,8 $\times 2,5 \mathrm{~cm}$; endosperma homogeneo.

ovitora oy

Bacia amazônica e Guianas, na terra firme em floresta tropical úmida.

Henderson 658 (fr.); Henderson \& Scariot 1162 (fr.).

4. Bactris hirta Mart., Hist Nat. Palm. 2: 104. (1823).

\section{"Marajá".}

- intshlising zarol

Estipe solitário ou cespitosó, até 2 $m$ de altura, até $1 \mathrm{~cm}$ de diâmetro! Folhas até 7 ; bainha aberta, até $20 \mathrm{~cm}$ de comprimento; pecíolo até $25 \mathrm{~cm}$ de comprimento; ráquis até $50 \mathrm{~cm}$ de comprimento; pinas de diferentes larguras e irregularmente dispostas, ou todas unidas em uma folha inteira bífida no ápice, folha hirta na face abaxial. Inflorescência infrafoliar, ereta na ântese e frutificação; bráctea peduncular até 8 $\mathrm{cm}$ de comprimento, densamente coberta externamente com espinhos negros; ráquilas 2-3; flores estaminadas com cálice trilobado; pétalas unidas na base; estames 6; flores pistiladas regularmente dispostas na base das ráquilas; cálice pequeno, anelar; corola mais comprida, urceolada; fruto globoso, vermelho a quase negro quando maduro, 6-7 mm de diâmetro.

Distribuída no norte da América do Sul, em terra firme na floresta tropical úmida.

Henderson 666 (f1.); Henderson 667 (fl.); Henderson \& Scariot 1151 (fl.).

5. Bactris humilis (Wallace) Burret, Feddes Rep. 34: 182. (1933).

Astrocaryum humile Wallace, Palm Trees of the Amazon 15. (1953).
Cizs: "Marajá".

Estipe solitário ou cespitoso, subterrâneo ou ocasionalmente até 50 cm đe altưfa, até $4 \mathrm{~cm}$ de diâmetro. Fölhas até 12 ; bainhas abertas, até 30 cm de comprimento; pecíolo até $1,4 \mathrm{~m}$ de comprimento; ráquis até $1,7 \mathrm{~m}$ de comprimento; pinas até 20 por lado, agrupadas, mas mais ou menos no mèsmo plano, sígmóides. Inflorescênciás interfoliares; pedúnculo até 17 cm de comprimento; prófilo até $10 \mathrm{~cm}$ de comprimento; bráctea peduncular até $20 \mathrm{~cm}$ de comprimento, densamente espinhosa na superfície externa; ráquis até $5 \mathrm{~cm}$ de comprimento; ráquilas até 40 , inclinada; flores estaminadas com 6 estames; flores pistiladas regularmente dispostas na base das ráquilas; sépalas e pétalas urceoladas, corola muito mais longa que o cálice; anel estaminodal ausente; fruto globoso, 1 $\mathrm{cm}$ de diâmetro, vermelho-laranja quando maduro, coberto com espinhos curtos; endosperma homogêneo.

Distribuída no Norte da América do Sul, ocorrendo em terra firme na floresta tropical úmida.

Henderson 657 (fr.); Henderson 671 (fr.); Henderson \& Scariot 1159 (fr.).

6. Bactris monticola Barb. Rodr. Enum. Palm. Nov. 34. (1875).

\section{"Marajá".}

Estipes cespitosos, 6-7 $\mathrm{m}$ de altura, 3-5 cm de diâmetro. Folhas 5-9; bainhas abertas, com espinhos amarelados fortemente achatados; pecíolo 50 $60 \mathrm{~cm}$ de comprimento, com espinhos similares aos da bainha; ráquis 130 - 
$150 \mathrm{~cm}$ de comprimento; pinas 20-22 por lado, agrupadas, em grupos de 25 , dispostas em um plano, lineares a sigmóides. Inflorescência interfoliar; pedúnculo $18-30 \mathrm{~cm}$ de comprimento; prófilo $20-26 \mathrm{~cm}$ de comprimento; bráctea peduncular $30-38 \mathrm{~cm}$ de comprimento com espinhos amarelados espalhados externamente; ráquis muito curto com 6-20 ráquilas; flores estaminadas com 3 sépalas, 3 pétalas, e 6 estames; flores pistiladas espalhadas entre flores estaminadas pareadas ou solitárias, com cálice cupular e corola; frutos globosos, $1,5 \mathrm{~cm}$ de diâmetro, negro-purpúreo.

Distribuída no Norte da América do Sul, na terra firme em floresta tropical úmida.

Henderson 669(est.); Henderson \& Scariot 1172 (est.).

7. Bactris simplicifrons Mart., Hist. Nat. Palm. 2: 103. (1823).

Palmeira espinhosa ou espinhos ausentes exceto nas margens das pinas.Estipes cespitosos, até $2 \mathrm{~m}$ de altura, 7-10 mm de diâmetro. Folhas 59; bainha aberta, 15-17 cm de comprimento; pecíolo $20-25 \mathrm{~cm}$ de comprimento; ráquis até $25 \mathrm{~cm}$ de comprimento; pinas poucas, de diferentes larguras, ou geralmente lâmina inteira. Inflorescência infrafoliar, pendente na ântese e na frutificação; pedúndulo $3-4 \mathrm{~cm}$ de comprimento; prófilo $3-4 \mathrm{~cm}$ de comprimento; bráctea peduncular ca. de 8 $\mathrm{cm}$ de comprimento, geralmente sem espinhos; ráquis não ramificado ou raramente com 2-4 ráquilas; flores estaminadas com um pequeno cálice tri-lobado; pétalas unidas na base; esta- mes 6; flores pistiladas regularmente dispostas na base das ráquilas; cálice e corola urceolados, mais ou menos iguais; anel estaminodal ausente; fruto globoso, vermelho quando maduro, 7$8 \mathrm{~mm}$ de diâmetro; endosperma homogêneo.

Distribui-se no Norte da América do Sul, em terra firme na floresta tropical úmida, e também em áreas abertas.

Henderson 663 (fr.); Henderson \& Scariot 1171 (fl.).

8. Bactris sphaerocarpa Trail, J. Bot. 6: 8, (1877).

Estipes cespitosos, 1,2-1,8 $\mathrm{m}$ de altura, 6-8 $\mathrm{mm}$ de diâmetro. Folhas 46; bainha e pecíolo com poucos espinhos ou quase glabro; ráquis ca. de $60 \mathrm{~cm}$ de comprimento; pinas 3-4 por lado, linear-lanceoladas. Inflorescência interfoliar; bráctea peduncular 10-20 $\mathrm{cm}$ de comprimento; ráquila 1-2; flores estaminadas com 3 sépalas, 3 pétalas, e 6 estames; flores pistiladas com cálice cupular e corola; frutos globosocomprimidos, $1,2-1,8 \times 1,5-1,8 \mathrm{~cm}$, negro-purpúreos na maturidade.

Distribuída na Amazônia Central, geralmente em terra firme na floresta tropical úmida.

Henderson 665 (est.); Henderson 677 (est.); Henderson 679 (est.).

\section{DESMONCUS Mart.}

Burret, M. 1934, Bactris und verwandte Palmengattungen. Repert. Spec. Nov. Regni Veg. 34: 167-184, 186-253.

Gênero de cerca de 12 espécies na América Central e do Sul. 
1. Desmoncus polyacanthos Mart., Hist. Nat. Palm. 2: 85. (1824).

\section{"Jacitara".}

Estipes cespitosos, de comprimento variável, ca. de $1 \mathrm{~cm}$ de diâmetro, trepador ou escandente. Folhas de número variável, com espinhos curtos e recurvados; bainha fechada, ca. de $30 \mathrm{~cm}$ de comprimento; pecíolo ca. de $15 \mathrm{~cm}$ de comprimento; ráquis ca. de $80 \mathrm{~cm}$ de comprimento; pinas 4 12 por lado, lineares a ovadas, as distais modificadas em ganchos recurvados. Inflorescência interfoliar; pedúnculo ca. de $30 \mathrm{~cm}$ de comprimento; prófilo ca. de $15 \mathrm{~cm}$ de comprimento; bráctea peduncular ca. de 28 $\mathrm{cm}$ de comprimento; ráquis ca. de 11 $\mathrm{cm}$ de comprimento; ráquilas 5-9, até $9 \mathrm{~cm}$ de comprimento; flores estaminadas com 3 sépalas, 3 pétalas, e 6 estames; flores pistiladas com sépalas conatas em um cálice cupular; pétalas similares; frutos elipsóides, 0,8-1,5 x $1-2 \mathrm{~cm}$, vermelho brilhante quando maduro.

Distribuído no Oeste da bacia amazônica, na Bolívia, Brasil, Colômbia, Equador, Peru e Venezuela.

Henderson 660 (est.); Henderson \& Scariot 1153 (est.).

\section{EUTERPE Mart.}

Burret, M. 1929. Die Gattung Euterpe. Gaertn. Bot. Jahrb. Syst. 63; 49-76.

Gênero com cerca de 6 espécies distribuídas desde o sul da América Central até a Bolívia e através da bacia amazônica, e também nas Antilhas Menores, alcançando o NE da Argentina e E do Paraguai.

1. Estipe solitário; coroa foliar verde; eófilo com pinas; frutos $1-1,2 \mathrm{~cm}$ de diâmetro; superfície abaxial do pecíolo e ráquis com pequenas escamas espalhadas; pinas pendentes

2. E. precatoria

1. Estipes cespitosos ou solitários; coroa foliar avermelhada; eófilo bífido; frutos $0,8 \mathrm{~cm}$ de diâmetro; superfície abaxial do pecíolo e ráquis com grandes e numerosas escamas; pinas espalhadas horizontalmente........... 1. E. catinga

1. Euterpe catinga Wallace, Palm Trees of the Amazon 27. (1853).

"Açai chumbinho".

Estipe cespitoso ou solitário, 5-11 $\mathrm{m}$ de altura, $3,5-8 \mathrm{~cm}$ de diâmetro. Folhas 5-10; bainhas fechadas, formando uma coroa de coloração alaranjada, com escamas negras apicalmente; pecíolo 3$17 \mathrm{~cm}$ de comprimento, com escamas negras; ráquis 1,2-2,4 $\mathrm{m}$ de comprimento; pinas 38-56 por lado, regularmente dispostas e no mesmo plano, espalhadas horizontalmente. Inflorescência infrafo- liar; pedúnculo 7-9 $\mathrm{cm}$ de comprimento; prófilo e bráctea peduncular da mesma cor que a bainha; ráquis $20-30 \mathrm{~cm}$ de comprimento; ráquila $48-87$, até $60 \mathrm{~cm}$ de comprimento, tomento marrom claro; flores em tríades; flores estaminadas com 3 sépalas livres e imbricadas e 3 pétalas livres e valvares; estames 6; pistilódio trífido; flores pistiladas com 3 sépalas e pétalas similares, imbricadas; frutos globosos, negros, $8 \mathrm{~mm}$ de diâmetro; endosperma homogêneo; embrião subbasal; eófilo bífido. 
Confinada à região do Rio Negro, no Brasil e Sul da Venezuela. Geralmente crescendo em áreas mal drenadas em solos arenosos, tanto em baixas como em altas (800-1100 m nos Tepuis) elevaçães.

Henderson \& Scariot 1169 (fl.).

2. Euterpe precatoria Mart. in Orbigny, Voy. Amérique Mér. 7(3). Palmiers 10. (1842).

"Açai".

Estipe solitário, 5-20 m de altura, 5-20 cm de diâmetro. Folhas 8-18; bainhas fechadas, formando uma coroa foliar, 96-164 cm de comprimento; pecíolos geralmente curtos ou ausentes, ocasionalmente $19-54 \mathrm{~cm}$ de comprimento; ráquis 2-3,2 $\mathrm{m}$ de comprimento; pinas $61-93$ por lado, regularmente espaçadas e no mesmo plano, pendentes. Inflorescência infrafoliar; pedúnculo 7$23 \mathrm{~cm}$ de comprimento; prófilo e bráctea peduncular similares, sub-iguais, 70-90 $\mathrm{cm}$ de comprimento; ráquis $34-70 \mathrm{~cm}$ de comprimento; ráquilas $70-178$, distri- buídas em todos os ângulos, densamente cobertas por tomento esbranquiçado; flores em tríades; flores estaminadas com 3 sépalas livres e imbricadas, e 3 pétalas valvares e livres; pistilódio trífido; flores pistiladas com 3 sépalas e pétalas similares, imbricadas; estaminódios ausentes; fruto globoso, negro, $12-14 \mathrm{~mm}$ de diâmetro; endosperma homogêneo; embrião sub-basal; eófilo pinado.

Comum desde o sul da América Central até a Bolívia através da bacia amazônica, ocorrendo em terra firme, mas também nas margens de rios.

$\mathrm{O}$ palmito é usado para alimentação, e os frutos para fazer bebidas.

Henderson \& Scariot 1168 (fr.).

\section{GEONOMA Willd.}

Wessels Boer, J. G. 1968. The Geonomoid Palms. Verh. Kon. Ned. Akad. Wetensch., Afd. Natuurk., Tweede Reeks 58(1): 1-202.

Gênero com cerca de 80 espécies espalhadas pelos Neotrópicos.

1. Inflorescểncia espigada

5. G. pycnostachys

1. Inflorescência ramificada.

2. Inflorescência com 2-5 ráquilas

1. G. aspidiifolia

2. Inflorescência com numerosas ráquilas.

3. Folhas inteiras, ou quase inteiras, firmes e eretas 6. G. spixiana

3. Folhas regularmente ou irregularmente pinadas.

4. Anelestaminodal crenulado 2. G. deversa

4. Anel estaminodal digitalmente lobado.

5. Frutos verdes; folhas regularmente pinadas 4. G. maxima

5. Frutos purpúreos; folhas com 2-3 pinas amplas 3. G. juruana 
1. Geonoma aspidiifolia Spruce, J. Linn. Soc., Bot. 11: 112. (1871). "Ubim"

Estipe cespitoso, 1,5-3 m de altura, até $1 \mathrm{~cm}$ de diâmetro. Folhas $8-12$; bainha aberta, $10-11 \mathrm{~cm}$ de comprimento; pecíolo $20-22 \mathrm{~cm}$ de comprimento; ráquis ca. de $20 \mathrm{~cm}$ de comprimento; pinas 2-3, amplas, ou folha inteira. Inflorescências infrafoliares; pedúnculo 4,6-6 cm de comprimento; e bráctea peduncular subiguais, 4-6 cm de comprimento; ráquis muito curto com (1-)2-5 ráquilas, estas de até $10 \mathrm{~cm}$ de comprimento; flores em tríades em cavidades; flores estaminadas com 6 estames; flores pistiladas com tubo estaminodal crenulado; fruto globoso, $6 \mathrm{~mm}$ de diâmetro, vermelho-escuro ou purpúreo-vermelho.

Ocorre em florestas de terra firme na Amazônia Ocidental.

Henderson 655 (fl.); Henderson \& Scariot 1152 (fl, fr.).

2. Geonoma deversa (Poit.) Kunth, Enum. Pl. 3: 231. (1841).

Gynestum deversum Poit., Mém. Mus. Hist. Nat. Paris 9: 390. (1822). "Ubim"

Estipe cespitoso, 3-4 m de altura, 1-2 cm de diâmetro. Folhas 7-10; bainha aberta, $13-15 \mathrm{~cm}$ de comprimento; pecíolo $15-40 \mathrm{~cm}$ de comprimento; ráquis 43 $50 \mathrm{~cm}$ de comprimento; pinas tipicamente 3 , amplas, ocasionalmente mais ou menos inteiras. Inflorescências infrafoliares; pedúnculo ca. de $15 \mathrm{~cm}$ de comprimento; prófilo e bráctea peduncular subiguais, $5-10 \mathrm{~cm}$ de comprimento; ráquis $7-15 \mathrm{~cm}$ de comprimento; ráquilas poucas e simples a numerosas e rami- ficadas; flores em tríades, em cavidades; flores estaminadas com tubo estaminodal crenulado; fruto globoso, negro, $6-7 \mathrm{~mm}$ de diâmetro.

Espalhada nos neotrópicos desde América Central até Bolívia através da bacia amazônica. Muito comum em terra firme, na floresta tropical úmida.

3. Geonoma juruana Dammer, Verh. Bot. Ver. Brandenb. 48: 119. (1906).

"Ubim"

Estipe cespitoso, 3-6 $\mathrm{m}$ de altura, 1,5-2 $\mathrm{cm}$ de diâmetro. Folhas 4-9; bainha aberta, $15-20 \mathrm{~cm}$ de comprimento; pecíolo $50-89 \mathrm{~cm}$ de comprimento; ráquis $40-60 \mathrm{~cm}$ de comprimento; pinas poucas, geralmente 2 ou ocasionalmente mais, ou folha inteira. Inflorescência interfoliar; pedúnculo 10-12 cm de comprimento; prófilo e bráctea peduncular subiguais, 12-15 $\mathrm{cm}$ de comprimento; ráquis ca, $10 \mathrm{~cm}$ de comprimento; ráquilas ramificadas; flores em tríades, em cavidades: as estaminadas com 6 estames; as pistiladas com um tubo estaminodal lobado digitalmente; fruto subgloboso ou elipsóide, negro-purpúreo, $1 \times 1,3 \mathrm{~cm}$.

Amazônia Ocidental no Brasil e Peru, em terra firme na floresta tropical úmida.

Henderson 670(fl.); Henderson 678(fl.); Henderson \& Scariot 1161 (fl.).

4. Geonoma maxima (Poit.) Kunth, Enum. Pl. 3: 229. (1841).

Gynestum maximum Poit., Mém. Mus. Hist. Nat. Paris 9: 388. (1822). "Ubim"

Estipe cespitoso, 5-6 m de altura, 
2,5-3 cm de diâmetro. Folhas 6-11; bainha aberta, $15-20 \mathrm{~cm}$ de comprimento; pecíolo $50-70 \mathrm{~cm}$ de comprimento; ráquis 1-1,2 $\mathrm{m}$ de comprimento; pinas lineares, regularmente dispostas em um plano, ocasionalmente irregulares. Inflorescência interfoliar; pedúnculo ca. de $16 \mathrm{~cm}$ de comprimento; prófilo e bráctea peduncular subiguais, 12-16 $\mathrm{cm}$ de comprimento; ráquis ca. $15 \mathrm{~cm}$ de comprimento; ráquila ramificada, 7 43; flores em tríades, em cavidades; flores estaminadas com 6 estames; flores pistiladas com um tubo estaminodal lobado digitalmente; frutos globosos ou ovóides, verde-amarelado, $1 \times 1,5 \mathrm{~cm}$.

Distribuída em terra firme na floresta tropical úmida através da bacia amazônica e Guianas.

Henderson 664 (fl.); Henderson \& Scariot 1163 (fl.).

5. Geonoma pycnostachys Mart., Hist. Nat. Palm. 2: 16. (1823).

Estipe cespitoso, 1-2 $\mathrm{m}$ de altura, ca. de $1 \mathrm{~cm}$ de diâmetro. Folhas 5-11; bainha e pecíolo até $19 \mathrm{~cm}$ de comprimento; ráquis até $31 \mathrm{~cm}$ de comprimento; lâmina inteira, até $37 \mathrm{~cm}$ de comprimento, bífida no ápice. Inflorescências interfoliares; pedúnculo ca. de $5 \mathrm{~cm}$ de comprimento; prófilo ca. de $8 \mathrm{~cm}$ de comprimento; bráctea peduncular ausente; ráquila até $7 \mathrm{~cm}$ de comprimento; flores em cavidades; flores estaminadas com 3 sépalas, 3 pétalas, e 6 estames; flores pistiladas com 3 sépalas, 3 pétalas; frutos ovóides, $6 \mathrm{x}$ $11 \mathrm{~mm}$, azuis quando maduros.

Espalhada na bacia amazônica, geralmente em terra firme na floresta tropical úmida, ou ocasionalmente em áreas inundadas.

Henderson 662 (fl.).

6. Geonoma spixiana Mart., Hist. Nat, Palm. 2: 15. (1823).

"Ubim".

Estipe solitário ou cespitoso, até $5 \mathrm{~m}$ de altura, $2-3 \mathrm{~cm}$ de diâmetro. Folhas 10-20; bainha aberta, $15-24 \mathrm{~cm}$ de comprimento; pecíolo $8-20 \mathrm{~cm}$ de comprimento; ráquis ca. de $1 \mathrm{~m}$ de comprimento; pinas muito largas, poucas, parecendo inteiras, duras e fortemente plicadas. Inflorescência interfoliar; pedúnculo $17-22 \mathrm{~cm}$ de comprimento; prófilo e bráctea peduncular sub-iguais, $18-22 \mathrm{~cm}$ de comprimento; ráquis $10-15 \mathrm{~cm}$ de comprimento; ráquila ramificada; flores em tríades, em cavidades; flores estaminadas com 6 estames; flores pistiladas com tubo estaminodal lobado digitalmente; fruto globoso ou elipsóide, 1 x 1,5 cm.

Partes Ocidental e Central da Amazônia, em terra firme na floresta tropical úmida.

Henderson 659 (fl.).

\section{HYOSPATHE Mart.}

Skov, F. \& H. Balslev. 1989. A revision of Hyospathe (Arecaceae). Nord. J. Bot. 9: 189-202.

Gênero com 2 espécies distribuídas do sul do Panamá ao Peru, através da Amazônia.

1. Hyospathe elegans Mart., Hist. Nat. Palm. 2: 1. (1823).

Estipe cespitoso, 2-8 $\mathrm{m}$ de altura, 
2-4 cm de diâmetro, ereto ou muito fino. Folhas 2-10; bainha fechada, formando uma coroa alongada, $40-50 \mathrm{~cm}$ de comprimento; pecíolo $28-40 \mathrm{~cm}$ de comprimento; ráquis ca. de $1 \mathrm{~m}$ de comprimento; pinas variando de regular a irregularmente pinadas à folhas quase inteiras. Inflorescência infrafoliar na ântese; pedúnculo $10-15 \mathrm{~cm}$ de comprimento; prófilo $22-40 \mathrm{~cm}$ de comprimento; bráctea peduncular $40-50 \mathrm{~cm}$ de comprimento; ráquis $10-16 \mathrm{~cm}$ de comprimento; ráquilas $10-31,33-45 \mathrm{~cm}$ de comprimento, espalhando-se na ântese; flores em tríades; flores estaminadas com curtos pedicelos; sépalas 3 , conatas; pétalas 3 , valvares; estames 6 ; pistilódio até $2 \mathrm{~mm}$ de comprimento; flores pistiladas sésseis; sépalas 3 , conatas; pétalas 3, imbricadas; estigmas 3 , sésseis, fruto ovóide a globoso, 3-7 x 6$16 \mathrm{~mm}$, negro.

Amplamente distribuída em vários habitats. Na Reserva Florestal Ducke ocorre em áreas inundadas.

Henderson 676 (fr.).

\section{IRIARTELLA H. A. Wendl.}

Henderson, A. 1990. Arecaceae Part I. Introduction and Iriarteinae. Flora Neotropica Monograph 53: 1-100.

Gênero de 2 espécies encontradas na parte ocidental da bacia amazônica.

1. Iriartella setigera (Mart.) H. A. Wendl., Bonplandia 8: 104. (1860).

Iriartea setigera Mart., Hist. Nat. Palm. 2: 39, (1824),

\section{"Pachiubinha".}

Estipes cespitosos, até $12 \mathrm{~m}$ de altura, $2-4 \mathrm{~cm}$ de diâmetro, unidos por longos rizomas negros, suportados por um cone de raízes adventícias, estas de até $50 \mathrm{~cm}$ de comprimento e $0,5 \mathrm{~cm}$ de diâmetro. Folhas 6-8; bainha fechada, formando coroa foliar, $15-40 \mathrm{~cm}$ de comprimento, coberta com pelos penetrantes; pecíolo $14-30 \mathrm{~cm}$ de comprimento; ráquis $34-96 \mathrm{~cm}$ de comprimento; pinas 5-9 por lado, cuneadarômbica com margens premorsas no ápice. Inflorescência interfoliar na ântese; pedúnculo $25-53 \mathrm{~cm}$ de comprimento; prófilo ca. de $16 \mathrm{~cm}$ de comprimento; brácteas pedunculares 3-4, 8-40 $\mathrm{cm}$ de comprimento; ráquis ca. $14 \mathrm{~cm}$ de comprimento; ráquilas 3-25, 8-22 $\mathrm{cm}$ de comprimento; flores em tríades; perianto das flores estaminadas verde; sépalas conatas em uma cúpula; pétalas 3, valvares; estames 6; pistilódio diminuto ou ausente; perianto das flores pistiladas verde; sépalas 3 , formando um cálice 3-lobado; pétalas 3 , imbricadas; estigmas 3 , sésseis; estaminódios diminutos ou ausentes; fruto elipsóide, vermelho-laranja quando maduro, 0,7-1 x 1,4-1,7 cm; embrião apical; eófilo inteiro.

Distribuída na floresta tropical úmida no Ocidente da Amazônia Central no Brasil, Colômbia, Venezuela, e alcançando a Guiana.

Henderson 681 (fr.).

\section{MANICARIA Gaertner}

Bailey, L. H. 1933. Certain palms of Panama. Gentes Herb. 3: 33116.

Gênero monoespecífico, distribuído da América Central à bacia amazônica. 
1. Manicaria saccifera Gaertner, Fruct. Sem. Pl. 2: 468. (1791).

\section{"Bussu"}

Estipe cespitoso ou solitário, 0,5$6 \mathrm{~m}$ de altura, $15-19 \mathrm{~cm}$ de diâmetro, geralmente coberto com folhas velhas, persistentes. Folhas 5-25, eretas; bainha aberta, $60-100 \mathrm{~cm}$ de comprimento; pecíolo $25-130 \mathrm{~cm}$ de comprimento; ráquis $3-4 \mathrm{~m}$ de comprimento; pinas fundidas para formar uma folha inteira, dividindo-se com a idade. Inflorescência interfoliar; pedúnculo $0,65-1,3 \mathrm{~m}$ de comprimento; prófilo ca. de $70 \mathrm{~cm}$ de comprimento; bráctea peduncular $81-90 \mathrm{~cm}$ de comprimento, como uma rede, não abrindo, porém persistente e continuando fechada sobre a inflorescência, abrindo assim que os frutos se formam; ráquis $35-60 \mathrm{~cm}$ de comprimento; ráquilas 24-37, estreitamente agrupadas na ântese; flores estaminadas ligeiramente imersas e cercadas pelas brácteas; estames 20-34; flores pistiladas em menor número, geralmente próximas à base das ráquilas; fruto globoso ou 2-3 lobado, 1-3 sementes, $4-5 \mathrm{~cm}$ de diâmetro, com exocarpo densamente protuberante e corticoso.

Geralmente em áreas baixas próximo a água, em floresta tropical úmida desde a América Central até o alto Amazonas.

\section{MAURITIA L. f.}

Burret, M. 1935. Die Palmengattung Mauritia L. f. und

Mauritiella Burret gen. nov. Notizbl. Bot. Gart. Berlin-Dahlem 12: 605-611.

Gênero com duas espécies confi- nadas aos Neotrópicos e distribuídas no norte da América do Sul.

1. Mauritia flexuosa L. f., Suppl. PI. 454. (1782).

\section{"Buriti".}

Estipe solitário, 4-25 m de altura, 23-50 cm de diâmetro, liso. Folhas 9-14; bainha aberta com poucas fibras nas margens; bainha e pecíolo $1,2-3 \mathrm{~m}$ de comprimento; lâmina costapalmada, com 120-227 segmentos, estes com 2-2,25 m de comprimento, pendentes próximo ao ápice. Inflorescência interfoliar, unissexual (plantas dióicas); pedúnculo 1-2,5 $\mathrm{m}$ de comprimento, coberto com numerosas brácteas tubulares; ramos secundários 18-36; ráquilas muito curtas com flores agrupadas; flores estaminadas com cálice tubular e 3 pétalas livres, valvares; estames 6; flores pistiladas com cálice tubular e corolla tubular 3-lobada; fruto elipsóide, marrom, coberto com escamas, $4-5 \times 4-7 \mathrm{~cm}$.

Muito abundante no Norte da América do Sul, principalmente ao longo de curso d'água e em áreas inundadas.

Henderson \& Scariot 1173 (est.).

\section{MAURITIELLA Burret}

Burret, M. 1935. Die Palmengattung Mauritia L. f. und Mauritiella Burret gen. nov. Notizbl. Bot. Gart. Berlin-Dahlem 12: 605-611. 1935.

Gênero de três espécies confinadas aos Neotrópicos e distribuídas através do Norte da América do Sul.

1. Mauritiella aculeata (Kunth) Burret, Notizbl. Bot. Gart. BerlinDahlem 12: 609. (1935). 
Mauritia aculeata Kunth, Nov. gen. sp. 1: 311. (1816).

"Buritirana".

Estipes cespitosos, geralmente inclinados, 2-20 m de altura, 7,5-14 cm de diâmetro, próximo à base coberto com acúleos radiculares. Folhas 4-10; bainha aberta, $35-123 \mathrm{~cm}$ de comprimento; pecíolo $30-120 \mathrm{~cm}$ de comprimento; lâmina costapalmada, com 74100 segmentos, estes $0,8-1,2 \mathrm{~m}$ de comprimento, pendente próximo ao ápice, esparsamente espinhoso nas margens, face abaxial branco-cinza. Inflorescência interfoliar, unissexual (plantas dióicas); pedúnculo $22-60 \mathrm{~cm}$ de comprimento, coberto com brácteas pedunculares tubulares; ráquis com 1232 ramos secundários; ráquilas muito curtas; flores estaminadas com cálice tubular e 3 pétalas livres, alongadas e valvares; estames 6; flores pistiladas com cálice tubular curto e corola 3lobada, comprida e tubular; fruto ovóide, marrom, coberto com escamas, 2$3 \times 2,5-3,5 \mathrm{~cm}$.

Comum em áreas abertas, florestas, e margens de rios, em floresta tropical úmida.

\section{OENOCARPUS Mart.}

Balick, M. J. 1986. Systematics and economic botany of the OenocarpusJessenia (Palmae) complex. Adv, Econ. Bot. 3: 1-140.

Gênero com nove espécies distribuídas desde a costa Rica até Bolívia através da Amazônia.

1. Sementes com endosperma ruminado; estames (7)9-20, filamentos não inflexos no ápice, frutos e sementes geralmente elipsóides; ráquilas nunca avermelhadas; espata glabra, verde escura

2. O. bataua

1. Sementes com endosperma homogêneo; estames 6 , filamentos inflexos no ápice; frutos e sementes geralmente globosos; ráquilas avermelhadas na frutificação; espata pilosa, marrom.

2. Estipes solitários, 10-20 (25) m alt.;pinas em grupos e dispostas em diferentes ângulos 1. O. bacaba

2. Estipes cespitosos, 6-8 $\mathrm{m}$ alt.; pinas regularmente dispostas em um plano 3. O. minor

1.Oenocarpus bacaba Mart., Hist. Nat. Palm. 2: 24. (1823).

"Bacaba"

Estipe solitário, até $20 \mathrm{~m}$ de altura, $20-25 \mathrm{~cm}$ de diâmetro. Folhas 8-17; bainhas parcialmente fechadas, 0,6-1,1 m de comprimento; pecíolo 0,3$1 \mathrm{~m}$ de comprimento; ráquis $2,25-6 \mathrm{~m}$ de comprimento; pinas 75-179 por lado, agrupadas e dispostas em diferentes ângulos. Inflorescência infrafoliar na ântese, parecendo rabo-de-cavalo; pedúnculo $18-40 \mathrm{~cm}$ de comprimento; prófilo ca. de $25 \mathrm{~cm}$ de comprimento; ráquilas $103-200$, pendentes; flores em tríades; flores estaminadas com 3 sépalas conadas basalmente e 3 pétalas livres e valvadas; estames 6 ; flores pistiladas com 3 sépalas imbricadas e 3 pétalas similares; fruto globoso a 
globoso-alongado, 1,6-2,1 x 1,4-2,1 $\mathrm{cm}$; resíduo estigmático apical; endosperma homogêneo; eófilo bífido.

Distribui-se no Norte da América do Sul, geralmente em terra firme na floresta tropical úmida.

\section{Henderson 672 (fl.).}

2. Oenocarpus bataua Mart., Hist. nat. palm. 2: 23. (1823).

Jessenia bataua (Mart.) Burret, Notizbl. Bot. Gart. Berlin- Dahlem 10: 302. (1928).

\section{"Patauá".}

Estipe solitário, até $25 \mathrm{~m}$ de altura, $25-45 \mathrm{~cm}$ de diâmetro. Folhas 14-20; bainhas formando uma coroa, fibrosa nas margens, até $1,4 \mathrm{~m}$ de comprimento; pecíolo ca. de $1 \mathrm{~m}$ de comprimento; pinas 70-108 por lado, regularmente dispostas e no mesmo plano. Inflorescência em forma de rabo-de-cavalo; pedúnculo 19$50 \mathrm{~cm}$ de comprimento; prófilo 75-111 cm de comprimento; bráctea peduncular 1,5-2,3 m de comprimento; ráquis até 54 $\mathrm{cm}$ de comprimento; ráquilas 135-370, pendulares; flores em tríades; flores estaminadas com 3 sépalas imbricadas e 3 pétalas valvares; estames (7)9-20; flores pistiladas com 3 sépalas e pétalas imbricadas, similares; estaminódios ausentes; fruto ovóide-elipsóide, 2-2,7 x 2,5-4 cm; endosperma ruminado; embrião basal, muito grande; eófilo bífido.

Distribui-se no norte da América do Sul, geralmente na floresta tropical úmida em áreas inundadas, mas ocasionalmente na terra firme.

A redução de Jessenia em Oenocarpus se deve a presença de caracteres intermediários encontrados em três táxons colombianos: $O$. makeru Bernal, Galeano \& Henderson e $O$, simplex Bernal, Galeano \& Henderson, recentemente descritos, bem como observações em $O$. circumtextus Mart., impossibilitando assim a separação natural desses gêneros (Bernal, Galeano \& Henderson, 1991). Um óleo de alta qualidade é extraído dos frutos. As folhas são usadas para cobrir construçães.

Henderson \& Scariot 1167 (fl).

3. Oenocarpus minor Mart., Hist. Nat. Palm. 2: 25. (1823).

\section{"Bacabinha".}

Estipes cespitosos, 6-10 m de altura, $6-8 \mathrm{~cm}$ de diâmetro. Folhas 810 ; bainhas formando uma coroa, 50$60 \mathrm{~cm}$ de comprimento; pecíolo 40-45 $\mathrm{cm}$ de comprimento; 3,4-4 $\mathrm{m}$ de comprimento; pinas 54-79 por lado, regularmente espaçadas, ocasionalmente irregulares, e todas no mesmo plano. Inflorescência em forma de rabo-decavalo; pedúnculo $5-10 \mathrm{~cm}$ de comprimento; prófilo $30-35 \mathrm{~cm}$ de comprimento; bráctea peduncular ca. de 68 $\mathrm{cm}$ de comprimento; ráquis ca. de 2,5 $\mathrm{cm}$ de comprimento; ráquilas 29-33, pendulares; flores estaminadas com 3 sépalas e pétalas; estames 6 ; flores pistiladas com 3 sépalas imbricadas e 3 pétalas similares; fruto globosoovóide a elipsóide; 1-1,6 x 1,6-2,3 cm. negro, resíduo estigmático apical; endosperma homogêneo; eófilo bífido.

Distribui-se no Norte da América do Sul, geralmente ocorrendo em terra firme na floresta tropical úmida.

Henderson 661 (fl.); Henderson \& Scariot 1154 (fl.). 


\section{SOCRATEA Karsten}

Henderson, A. 1990. Arecaceae Part I. Introduction and the Iriarteinae. Flora Neotropica Monograph 53: 1-100.

Gênero de cinco espécies distribuídas desde o sul de Honduras até Bolívia, através da Amazônia.

1. Socratea exorrhiza (Mart.) H. A. Wendl., Bonplandia 8: 103. (1860).

Iriartea exorrhiza Mart., Hist. Nat. Palm. 2: 36. (1824).

\section{"Pachiúba"}

Estipe solitário, até $20 \mathrm{~m}$ de altura, $10-18 \mathrm{~cm}$ de diâmetro, suportado por um cone de até 25 raízes adventícias com acúleos, estas amplamente espaçadas e de até $2 \mathrm{~m}$ de comprimento. Folhas ca. de 7; bainhas fechadas, formando uma coroa, $90-150$ $\mathrm{cm}$ de comprimento; pecíolo $15-40 \mathrm{~cm}$ de comprimento; ráquis $1,4-2,8 \mathrm{~m}$ de comprimento; pinas $15-25$ por lado, ápice premorso, dividido em segmentos, estes dispostos em diferentes planos. Inflorescência infrafoliar na ântese; pedúnculo até $50 \mathrm{~cm}$ de comprimento; prófilo até $11 \mathrm{~cm}$ de comprimento; brácteas pedunculares 3-5, até $60 \mathrm{~cm}$ de comprimento; ráquilas até 17 , $30-40 \mathrm{~cm}$ de comprimento; flores em tríades; flores estaminadas esbranquiçadas; sépalas 3, pouco conadas; pétalas 3, valvares; estames (17-)30-45(65); flores pistiladas brancas na ântese; sépalas 3 , imbricadas; pétalas 3 , imbricadas; estigmas 3 , eretos na ântese; estaminódios ausentes; fruto ovóidecilíndrico, 1,5-2 x 2,5-3,5 cm; embrião apical; eófilo bífido.

É a espécie mais amplamente distribuída do gênero, desde Honduras até Bolívia através da Amazônia. Cresce em diversos habitats, sendo mais comum em floresta tropical úmida, em áreas inundadas ou em terra firme.

Tábuas do estipe são usadas como ripas na construção de casas, assim como paredes ou pisos.

Henderson \& Scariot 1166 (fr.).

\section{SYAGRUS Mart.}

Glassman, S. F. 1987. Revisions of the palm genus Syagrus Mart. and other selected genera in the Cocos alliance. Illinois Biological Monographs 56: $1-230$.

Gênero com 29 espécies, distribuídas desde o sul da Colômbia até Uruguai, e também conhecida das Antilhas Menores.

1. Syagrus inajai (Spruce) Becc., Agric. Colon. 10: 467. (1916).

Maximiliana inajai Spruce, $\mathbf{J}$. Linn. Soc., Bot. 11: 163. (1871).

\section{"Inajai"}

Estipe solitário, 8-12 $\mathrm{m}$ de altura, ca. de $10 \mathrm{~cm}$ de diâmetro. Folhas 11-15; bainhas abertas, $70-75 \mathrm{~cm}$ de comprimento; pecíolo 0,5-1 m de comprimento; ráquis ca. $3 \mathrm{~m}$ de comprimento; pinas 84-94 por lado, em grupos de 2-4, dispostas em diferentes ângulos. Inflorescência interfoliar na ântese; pedúnculo ca. de $60 \mathrm{~cm}$ de comprimento; prófilo ca. $30-55 \mathrm{~cm}$ de comprimento; bráctea peduncular espessa e lenhosa; ráquis ca. de $40 \mathrm{~cm}$ de comprimento; ráquilas até 65 , espalhadas; flores em tríades na parte basal das ráquilas; flores estaminadas com 3 sépalas triangulares e 3 pétalas 
valvares, livres; estames 6; pistilódio ausente; flores pistiladas com 3 sépalas e pétalas imbricadas, livres; fruto ovóide, 2,4-3 x 3,5-4 cm; endosperma homogêneo.

Espécie da terra firme em floresta tropical úmida, ocorrendo na bacia amazônica e nas Guianas.

Henderson \& Scariot 1157 (fr.).

\section{Literatura Citada}

ALENCAR, J, C. - 1986, Análise de Associaçāo e Estrutura de uma Comunidade de Floresta Tropical Úmida onde Ocorre Aniba rosaeodora Ducke (Leguminosae). Tese de Doutorado em Silvicultura, INPA-Fundação Universidade do Amazonas. 332 p.

BERNAL, R. G.; GALEANO, G.; HENDERSON, A. - 1991. Notes on Oenocarpus (Palmae) in the Colombian Amazon. Brittonia, 43(3):154-164.

HENDERSON, A. \& BALICK, M. - 1991. Attalea crassispatha, a rare and endemic Haitian palm. Brittonia, 43(3):189-194.

LEWIS, G. P.; OWEN, P. E. - 1989. Legumes of the llha de Maracá. Royal Botanic Gardens, Kew, U.K. 95 p.

MARTIUS, K. F. P. von; EICHLER, A. W.; Urban, I. (eds.) - 1840 a 1906. Flora Brasiliensis. 15 volumes em 40 partes. 130 fascículos. Munique, Viena e Leipzig. 20.733 p.

NELSON, B, W; FERREIRA, C, A, C; DA SILVA, M. F.; KAWASAKI, M, L. 1990. Endemism centers, refugia and botanical collection density in Brazilian Amazonia. Nature, 845:714-716.

PRANCE, G. T,- 1990. The floristic composition of the forests of central Amazonian Brazil pag. 112-140 in: A. Gentry (ed.) Four Neotropical Forests. Yale University Press. New Haven. 627 p. 